10.1590/S1414-40772018000300012

Este é um artigo publicado em acesso aberto sob uma licença Creative Commons

https://creativecommons.org/licenses/by-nc/4.0/

\title{
Regulamentação e garantia de qualidade na educação superior: uma categoria de análise histórica
}

\author{
Glades Tereza Felix ${ }^{1}$
}

Resumo: Este artigo trata das práticas de asseguramento de garantia de qualidade no debate geral das políticas de educação superior. Objetiva-se problematizar a noção de qualidade das antigas universidades à era da globalização. De caráter descritivo, apresenta uma abordagem qualitativa, fundamentada nos aportes teóricos da Global University Network for Innovation (GUNI) e da Red Iberoamericana para la Acreditación de la Calidad de la Educación Superior (RIACES). Faz-se um resgate de como as universidades e a educação superior se desenvolveram em contextos de competição. Revisa-se o reconhecimento do Estado como principal responsável pela garantia do padrão de qualidade das universidades. Apresentam-se o modelo de acreditação norte-americano e a criação das Agências de Avaliação e Acreditação para a regulação da expansão do setor e a integração destas em Redes Internacionais de Agências balizadoras de critérios de qualidade. Conclui-se que as regulamentações pré-renascentistas são as bases da noção de garantia de qualidade; que o modelo de acreditação dos EUA é o mais conhecido e adaptado; e que o Processo de Bolonha representa a nova política internacional indutora de garantia da qualidade com reflexos além do continente europeu.

Palavras-chave: Regulamentação. Acreditação. Educação superior.

\section{Regulation and quality assurance in higher education: a category of historical analysis}

Abstract: This article deals with quality assurance practices in the general debate of higher education policies. The objective is to discuss the notion of quality of the oldest universities in the era of globalization. Of descriptive, with a qualitative approach, based on the theoretical contributions of the Global University Network for Innovation (GUNI) and Red Iberoamericana para la Calidad de la Accreditation de la Education Superior (RIACES). Becomes a rescue such as universities and higher education have developed in competitive contexts. Revises up the recognition of the state as the main responsible for the standard of quality assurance of universities. It presents the North American accreditation model and the establishment of the Assessment and Accreditation Agency for regulation of the sector's expansion and the integration of these networks in balizadoras agencies International quality standards. It concludes that the pre-Renaissance regulations are the basis of quality assurance notion; the US accreditation model is the best known and adapted and that the Bologna Process is the new politics international quality assurance inducing reflected beyond the European continent.

Key words: Regulatory. Accreditation. Higher education. 


\section{Introdução}

Neste texto, abordam-se as práticas de asseguramento de garantia de qualidade no debate geral das políticas de educação superior. A ideia é resgatar as origens da evolução do uso formal da regulamentação como meio de controle para o funcionamento do ensino superior. Objetiva-se, pois, problematizar a noção de qualidade das antigas universidades à era da globalização.

Para tanto, faz-se um resgate da universidade renascentista e da universidade moderna, passando pelo padrão de qualidade da universidade americana, para chegar-se à produção contemporânea de processos de regulação mais abertos, globais, flexíveis, menos nacionais e mais internacionais.

Destaca-se que foi a partir dos anos de 1990 que a maioria dos países de todos os continentes criou Agências de Avaliação e Acreditação, objetivando assegurar a qualidade da educação superior, o que se tornou uma necessidade frente à rápida expansão, massificação e ameaça de mercantilização do setor.

Frente a tais questões, as estratégias vão se aperfeiçoando e as Agências de Avaliação e Acreditação nacionais passam a integrar Redes Internacionais de Agências de Acreditação, as quais são acreditadas e certificadas pelos Estados e pelos organismos multilaterais e têm a missão de indicar parâmetros, critérios e os procedimentos metodológicos acerca da qualidade, como um padrão a ser seguido pelos parceiros.

Nesse âmbito, realizou-se uma investigação de cunho descritivo, com uma abordagem qualitativa, fundamentada nos aportes teóricos da Global University Network for Innovation (GUNI, 2009) e da Red Iberoamericana para la Acreditación de la Calidad de la Educación Superior (RIACES, 2013), em que se procedeu a uma pesquisa e encontraram-se mais de cem Redes Internacionais de Agências de Acreditação regulamentadoras da garantia da qualidade no ensino superior. Realizado o levantamento destas, apresentam-se, em forma de quadros por continente, a Rede e o país-sede; em seguida, problematiza-se a velocidade da expansão dessas redes, especialmente, após ser decretada a Declaração de Bolonha (1999).

\section{Regulamentação como controle da educação superior}

Ao longo do tempo, a busca da qualidade na educação superior tem sido prioridade de inúmeras esferas. Por isso, cada vez mais, desponta como de caráter urgente a evolução de mecanismos de controle, garantia e asseguramento da qualidade. 
Partindo dos primórdios das universidades, a principal raiz do moderno reconhecimento de garantia de qualidade, segundo Brock (2009), está nas regras, regulamentações e padrões ditados pelo patronato religioso ou secular às primeiras universidades pré-renascentistas.

Contudo, a difusão, o espalhamento e a expansão das universidades no período foram regulados a serviços de benefícios, exclusivamente, educativos. Qualquer interessado que tivesse a intenção de ter o status de Studium generale (Estudos gerais), no século XII, era obrigatório antes a recorrer ao Papa ou ao Rei, para obtenção de consentimento; sem essa précondição, era impossível qualquer instituição funcionar, regularmente.

As universidades na Europa renascentista não eram apenas produtos do renascimento da erudição greco-romana e cristã, mas também as herdeiras de uma longa história de educação superior a partir de uma esfera de outras civilizações, especialmente do Islã, com sua tradição inclusiva. Elas eram também produtos de uma segunda revolução urbana derivada da relativa estabilidade do início do período medieval, a qual permitia o crescimento do comércio e o acúmulo de riqueza naqueles locais que eram na verdade cidades-estados (BROCK, 2009, p. 161).

Com a valorização da educação, a classe média passou a ambicionar novos postos, como, por exemplo, ser docente, fato que aguçou a disputa de vagas nas universidades, o que provocou imediata reação da burguesia e de estudiosos, pois "preferiam manter as universidades exclusivas tanto quanto possível” (BROCK, 2009, p. 161). Assim, diversos tipos de providências foram implementadas pelos superiores, dentre as quais a prática de regulamentação, também denominada de credenciamento, reconhecimento e até garantia de qualidade, aplicadas sem critérios, com o objetivo claro de certidão de fé pública, porém sem sucesso.

Nesse espaço-tempo, é primordial destacar que foi no século XVIII (1794) que o Estado Prussiano decretou o documento denominado "Código Legal", cujo texto trata dos antecedentes legais da obrigatoriedade da anexação das universidades ao Estado, que, por competência, passou a controlar as qualificações educacionais. Portanto, o Estado era soberano em matéria de educação superior, apesar de esta ser mantida pela Igreja.

Foi nesse documento que constaram as regras e critérios do que representou a Acreditação naquela época. Segundo Brock (2009, p. 162), existia uma qualificação para lecionar nas universidades - ficentia ubique docendi ${ }^{1}$; portanto havia controle e regras para tal.

\footnotetext{
${ }^{1}$ Traduz-se por beneficência em todos os lugares do ensino.
} 
Porém, tal dispositivo legal teve pouco ou quase nenhum efeito regulatório em relação à carreira docente e ao controle e à garantia da qualidade, pois, contraditoriamente, o papel do Estado continuava a ser relativizado pela Igreja e pelo Rei, o que ficava evidente nas decisões políticas do uso de artifícios de não reconhecimento de certificados emitidos por instituições que não fossem locais. Outorgada pela centralidade do Estado, a autonomia era ferida, pois tal prática fazia reservas de vagas.

Foi assim que o pretenso controle de qualidade nas instituições renascentistas se resumiu em conflitos de intenções por meio do uso do poder e descrédito das instituições e no declínio da democracia e da autonomia.

Em contraponto, no século XIX, surgiu a Universidade Moderna, ${ }^{2}$ que inaugurou um ciclo expressivo para a educação superior. Contudo, a Igreja Católica continuava a ser a sua única mantenedora, utilizando, pois, a prática da regulamentação com o consentimento do Rei, para controlar e garantir a qualidade.

Pode-se dizer que esse período representou o esgotamento do uso da regulamentação local e a simulação de uma Acreditação em moldes nacionais, pois o modelo de universidade de caráter universal garantiu acesso aos interessados na carreira docente, abrindo, assim, frente de trabalho no magistério.

Entende-se que a finalidade da Igreja Católica era o controle do acesso dos docentes por meio da Regulamentação, pois, até então, não havia um debate sobre o regramento da qualidade dos serviços ofertados. Mais tarde, o poder real recupera seu direito de mantenedor, cujas instituições também passaram a depender da autorização máxima do poder civil, que, aliada ao clero, certamente, continuava a competição pelo controle da oferta.

Tais disputas se estenderam por todo o século XIX, gerando consideráveis atrasos na expansão de novas universidades. É certo que a proliferação das monarquias feudais refletiu, diretamente, nesse retrocesso. Apesar disso, tiveram os padres jesuítas, na época, destacada influência com a mobilidade de alunos pelo território europeu, o que, naturalmente, deu feição internacional aos padrões de qualidade.

Contudo, em pleno século XIX, os críticos reconheciam que os regulamentos eram rejeitados e que a educação era de qualidade bastante duvidosa, tornando-se isso um conformismo nacional.

\footnotetext{
${ }^{2}$ Originada das Escolas Medievais - Studia generalia (Estudos gerais) -, tal proposta de universidade surgiu para cobrir lacunas das Escolas Catedrais e Monásticas que formavam adeptos para seguir a vida religiosa.
} 
Foi a partir das ideias do alemão Humboldt ${ }^{3}$ que surgiram discordâncias aos padrões impostos ao modelo de universidade vigente. Isso foi possível porque ele se baseou na distinção entre academia e universidade, renovando a dimensão intelectual da nação, o que se refletiu também na universidade da Grã-Bretanha e dos Estados Unidos.

Com efeito, para Amaral (2010), isso foi importante, mas gerou um paradoxo, pois o conceito de liberdade acadêmica no modelo de universidade humboldtiana era totalmente incompatível com a ideia de controle implícito em processos de Avaliação ou de Acreditação.

De fato, Humboldt propôs uma noção de autonomia acadêmica, ou melhor, de liberdade acadêmica, que era individual e não institucional, em que o Estado atuava como tampão para impedir que os interesses externos (da sociedade, da igreja, dos políticos, etc.) interferissem com a liberdade da procura do conhecimento e da liberdade de ensinar e aprender, bem como o monopólio no acesso às carreiras da função pública (NEAVE; VUGHT, 1994, p. 271).

Assim, criaram-se as condições para a defesa e promoção da liberdade acadêmica com qualidade, pois a ideia de Humboldt foi a mais rica oportunidade para se (re)definir qualidade como processo e nunca como resultado, obviamente, antes de ter sido incorporada e ressignificada aos desafios linguísticos em níveis internacionais.

Em 1912, encontramos registros da Agência de Relatórios Especiais sobre Assuntos Educacionais do Conselho de Educação do Governo Britânico (BROCK, 2009, p. 161), que se reporta à existência de documentos como Programas, Estatutos e Regulamentações, demonstrando atenção com padrões de qualidade.

Outra ideia foi o modelo de universidade inglesa que teve forte apoio local e isenção da Igreja, mantendo difusa ligação com o Estado, porque este detinha soberania para outorgar diplomas através de uma Carta Real. O Estado inglês manteve vigorosa e firme fiscalização sobre as universidades e seu crescimento, tanto que foi neste período que se deu a criação da Fundação do Comitê de bolsas universitárias (University Grants Committee - UGC) na Inglaterra (BROCK, 2009, p. 160). Em 1919, essa instituição influenciou as universidades da época, sendo que algumas existem até hoje e, tradicionalmente, encontram-se na luta pela manutenção e "garantia de qualidade", acompanhando as novas tendências mundiais.

Pelas ideias antes expostas, percebe-se que foi a antiguidade europeia que deu uma vaga noção de controle e padrão de qualidade por meio de regulamentos outorgados pela Igreja e os Estados. Isso levou as universidades e a educação superior a se desenvolverem num contexto de competição por controle entre forças religiosas e políticas, cujos interesses

\footnotetext{
${ }^{3}$ Wilhelm Von Humboldt (1767-1835), na Reforma de 1809, criou a Universidade de Berlim, conhecida como modelo de universidade alemã, germânica ou humboldtiana.
} 
corporativos se constituíram num grande empecilho à melhoria da qualidade dos padrões da educação, das carreiras profissionais e das instituições de educação superior.

\section{Noção de controle e garantia de qualidade no modelo americano}

Na medida em que surgiram novas nações, suas bases culturais, políticas e geográficas procuraram melhorar a estruturação e o funcionamento da oferta do ensino superior, cujo foco central era o padrão de qualidade. Isso levou os governos a aumentar o controle e criar sistemas de garantia da qualidade mediante o uso de indicadores objetivos de desempenho.

$\mathrm{Na}$ América do Norte, especialmente nos Estados Unidos, o modelo da universidade inglesa deu base para as primeiras faculdades, as quais foram se moldando a um sistema de educação superior muito peculiar, pois contou com a independência do Estado, da Igreja e dos indivíduos, entrando em cena um novo parceiro: a empresa privada.

Foi assim, de modo inovador, que apareceu o setor empresarial como um elemento estratégico e articulador para o sucesso da busca da qualidade, cuja relação se constituiu na marca essencial da educação superior americana, ou seja, a associação entre educação superior, mercado e qualidade.

Pode-se observar que essa renovação da noção de qualidade do final do século XIX se originou de um "contexto econômico avançado de maneira exuberante", como comenta Brock (2009, p. 163), pois o setor sempre demonstrou preocupação pelo desenvolvimento da educação pública. Naturalmente, o ensino superior também incorporou a mesma prática a partir do que conhecemos hoje como Acreditação, ou seja, um tipo de autorregulamentação, o que representou uma revolução para a época.

Tal associação foi aceita e valorizada pelas instituições superiores, o que agregou para a formação de uma civilização universal, aberta e inovadora sustentada em padrões de erudição europeia, que, combinada ao ideal democrático de acesso a oportunidades educacionais em todos os níveis, para todos os cidadãos, integrou-se à noção de padrão de qualidade advinda do âmbito empresarial.

Contudo, o envolvimento de valores acadêmicos (modelo inglês) associados à natureza de interesses mercantis tornou mais complexa a busca da garantia de qualidade no sistema de ensino superior americano, porque não foram só doações de fabricantes e empresários bem-sucedidos que as instituições recebiam, mas, segundo Brock (2009, p. 161), também "experiências práticas organizacionais de grandes empresas". 
Em processos dessa natureza, pode-se questionar onde começa e onde se completa a questão da qualidade social e formativa. Será que os efeitos da confluência entre interesses acadêmicos e interesses mercantis serão o remédio para resolver a questão da melhoria da qualidade?

Se, por um lado, a prática da Acreditação com base no setor empresarial é um fato inegável que surgiu nos Estados Unidos, por outro, Scheele ${ }^{4}$ (2004, p. 10) argumenta que, bem antes da experiência americana, em outros moldes já ocorriam processos de Acreditação em sistemas educacionais da Europa Oriental (Rússia, Hungria e outros países).

O fato é que a raiz do asseguramento de padrões mínimos de qualidade, tal como se vivencia atualmente, nasceu numa fase de desenvolvimento econômico e educacional da história americana, porque soube inverter a prioridade da Igreja e do Estado ao procurar se autogovernar, autorregulamentar e autoavaliar-se.

Transcorrido um centenário da experiência americana, foi somente após a influência do neoliberalismo (1970) que a economia mundial despertou o interesse em projetos com base na noção de controle da qualidade das antigas escolas estudinenses, o que vai adaptar-se como uma luva aos interesses da conjuntura global. Portanto, não é por outro motivo que a maioria das nações que introduziram algum tipo de controle de garantia da qualidade no ensino superior após 1980 reproduziu tal esquema.

O movimento de garantia de qualidade foi em grande medida motivado pelo declínio da confiança no ensino superior. Tantos novos e diferentes tipos de instituições estavam entregando diplomas a uma população estudantil tão expandida que as partes interessadas começaram a questionar a comparabilidade dos diplomas. A falta de informação generalizada sobre o funcionamento interno das universidades e faculdades se tornou um motivo de preocupação (REISBERG, 2011, p. 17).

Pode-se dizer que foi a partir de elementos dessa natureza que emergiu um novo perfil para discussão da garantia de qualidade, uma vez que, para Harvey e Newton (2004 apud REISBERG, 2011, p. 3), "políticos oportunistas exploravam a incerteza dos alunos, contribuintes e empregadores em relação ao crescente investimento público", o que impõe ao ensino superior novas obrigações.

Com as novas exigências políticas e econômicas, foi se aperfeiçoando a prática de garantir a qualidade por meio da Acreditação. Atualmente, vigoram nos Estados Unidos, em

\footnotetext{
${ }^{4} \mathrm{O}$ autor, ao tratar dos desafios de garantia da qualidade no ensino superior, faz analogia aos seguintes filmes de James Bond: 1) Da Rússia com amor; 2) O mundo não é o bastante; 3) O homem com pistola de ouro; 4) Dr. No: pares ou mais; 5) Golden Eye: olho do carpinteiro e outros ponteiros para o método de trabalho; 6) Licença para matar; 7) Viva e deixe morrer; 8) Somente para seus olhos; 9) O amanhã nunca morre; 10) The living daylights ou morrer outro dia?; e 11) O espião que me amava.
} 
matéria de ensino superior, dois tipos de autorregulamentação: a) Acreditação por meio das associações de membros regionais que certificam a atividade das faculdades e universidades; e b) Acreditação das entidades de associações profissionais não lucrativas que avaliam e certificam programas de graduação individuais, as quais são geridas por organizações de associados. Dependendo da localização, as instituições deverão pertencer a uma das seis associações de membros regionais (REISBERG, 2011, p. 6).

Naquele contexto, as agências semigovernamentais são responsáveis pela coordenação dos processos de Acreditação, Auditorias e Avaliações externas, seguindo quase sempre o mesmo roteiro: realização de autoestudo, avaliação externa, recomendações do órgão administrativo e decisão.

Pela sua caracterização e peculiaridade, é um sistema que se destaca pela diversificação e hierarquização das Instituições de Ensino Superior (IES) que exercem papéis diferenciados. Assim, convivem nesse sistema tanto universidades tradicionais como uma série de instituições que oferecem cursos curtos e profissionalizantes para as camadas populares.

No caso dos EUA, por exemplo, a acreditação é voluntária, mas as instituições devem ser acreditadas para receber fundos do governo federal para ajuda financeira para pesquisa ou estudantes. Na maioria das áreas de estudo, os estudantes americanos devem se formar em programas de graduação acreditados para terem o direito de receber uma habilitação profissional, como na Argentina. No caso do Chile, a acreditação de programas é voluntária, mas extremamente útil já que a conclusão bem sucedida da avaliação fornece dados úteis para que os programas e instituições legitimem os pedidos por recursos adicionais (LEMAITRE, 2004 apud REISBERG, 2011, p. 6).

Também surgiu e vigora nos Estados Unidos o padrão denominado de Avaliação baseada na missão, que, para Reisberg (2011), procura acomodar a diversidade de IES e seus objetivos, porque uma instituição ou programa é avaliado em termos de seu sucesso em atingir os objetivos que fixou para si mesmo. Parte-se do pressuposto de que tal flexibilidade pode facultar muitos benefícios. Frente a essa generalidade, segundo Lemaitre (2004), até IES medíocres poderão ajustar seus objetivos para serem, naturalmente, atingidos.

Isso revela que os americanos, na verdade, separam Avaliação de Acreditação, visto que, para efeitos de mercado da educação superior, a Acreditação é mais benéfica em termos de competição, porque emite um selo de certificação da qualidade, sendo óbvio que as agências que acreditam as melhores universidades ganham nesse mercado. Isso justifica o fato de que a necessidade da Acreditação se tornou um instrumento de poder nas negociações com organismos internacionais, até porque, na ótica de Sousa Santos (2010), atesta a promoção do desenvolvimento educacional, econômico, social, político e cultural. 


\section{Redes internacionais de agências para o controle e garantia da qualidade}

A história nos dá conta de que a qualidade está, cada vez mais, no centro da agenda atual e nos debates mais ferrenhos da educação superior. Sendo, pois, a noção de qualidade um conceito não unívoco, importa determinar quais conceitos de qualidade orientam as práticas em uso nas universidades. Apesar da diversidade de definições que a literatura oferece, Dias Sobrinho (2006) é enfático em afirmar que duas concepções disputam, hegemonicamente, a direção da educação superior, ou seja, a perspectiva social na visão daqueles que concebem "a educação como bem público e o ponto de vista daqueles que submetem a educação ao mercado".

O evidente crescimento da oferta mundial de educação superior, a partir de dispositivos como novos tipos de provedores, a diferenciação de modelos institucionais, a diversificação de funções de serviços educativos e o incremento da educação a distância tornaram a área vulnerável à ameaça de massificação e mercantilização.

Desse modo, a Avaliação e a Acreditação se tornaram um ponto essencial para a Educação Superior, por isso em nível regional, nacional e internacional são apresentadas medidas para assegurar a qualidade e defender os países e os estudantes de ofertas educacionais duvidosas.

No intuito de separar o joio do trigo, a partir dos anos de 1990, surgiram Agências de Avaliação e Acreditação, em quase todos os países, as quais assumiram a incumbência, no plano burocrático-legal, de estabelecer, previamente, conceitos, parâmetros e critérios visando à efetividade dos processos de garantia de qualidade das instituições, dos cursos e dos diplomas.

Os governos aumentam os controles e os sistemas de garantia da qualidade e cada vez mais empregam indicadores objetivos de desempenho. Se a economia global aponta para uma qualidade genérica, internacionalmente comparável e compatível, então, as agências ou os organismos precisam operar como critérios e metodologias também globais e homologáveis, definidos por eles mesmos (DIAS SOBRINHO, 2006, p. 4).

Pode-se afirmar que a garantia do padrão de qualidade chegou com mais força por meio dos processos de Acreditação, cujas agências regionais e nacionais passaram a formar Redes Internacionais de Agências de Acreditação durante o século XX no mundo. Segundo Leite e Genro (2012, p. 6), esses aglomerados representam "a porta de entrada do novo imperialismo" e objetivam integrar regiões, nações e continentes, contribuindo para o 
desenvolvimento das capacidades institucionais de cada país, permitindo, de forma recíproca, a aferição da qualidade dos cursos ofertados nos países-membros e associados.

Indutora da mobilidade entre docentes, discentes e técnicos, permite a livre circulação de profissionais cujas carreiras são acreditadas em determinadas áreas, expandindo, assim, o mercado de trabalho no entorno global. Isso se relaciona à internacionalização e à transnacionalização do capital humano, da educação e do conhecimento fronteiriço.

Sobre isso, no site da Rede Ibero-americana para Acreditação da Qualidade na Educação Superior ${ }^{5}$ (RIACES, 2013), encontra-se um conjunto de Redes Internacionais de Agências de Acreditação em funcionamento em cinco continentes.

Para um melhor panorama da expansão, da distribuição e da maior ou menor concentração desses poderosos conglomerados de agências, apresentam-se, a seguir, em forma de quadros, o continente, a Rede e o país/sede, para em seguida discutir-se seus efeitos.

\footnotetext{
5 A Rede Ibero-americana para Acreditação da Qualidade da Educação Superior (RIACES) é uma associação sem fins lucrativos que reúne Agências de Avaliação e Acreditação de 18 países ibero-americanos e se destina a promover, entre os participantes, a cooperação e o intercâmbio em matéria de Avaliação e Acreditação da educação superior, contribuindo, assim, para a garantia da qualidade da educação superior nesses países.
} 


\section{Quadro 1 - Redes Internacionais de Agências de Acreditação no continente americano}

\begin{tabular}{|c|c|c|}
\hline \multicolumn{3}{|l|}{ CONTINENTE: Americano } \\
\hline \multicolumn{3}{|l|}{ Hemisfério Sul } \\
\hline REDE & SIGLA & PAÍS/SEDE \\
\hline $\begin{array}{l}\text { 1. Instituto Internacional para la Educación Superior en América } \\
\text { Latina y El Caribe }\end{array}$ & IESALC & Venezuela \\
\hline 2. Red Iberoamericana para la Acreditácion de la calidad & RIACES & Argentina \\
\hline 3. Rede de Agências Nacionais de Acreditação & RANA & \multirow[t]{2}{*}{ Uruguai } \\
\hline 4. Sistema Regional de Acreditação de Cursos de Graduação & ARCU-SUR & \\
\hline \multicolumn{3}{|l|}{ Hemisfério Central } \\
\hline 5. Dicción General de Acreditación y Certficación & DIGEACE & \multirow{2}{*}{ Guatemala } \\
\hline 6. Consejo Superior Universitário Centroamericano & CSUCA & \\
\hline $\begin{array}{l}\text { 7. Red Caribeña para El aseguramiento de La calidad em Educación } \\
\text { terciária }\end{array}$ & CANQATE & Jamaica \\
\hline 8. The University Council of Jamaica (UCJ) & $\mathrm{UC}$ & Jamaica \\
\hline $\begin{array}{l}\text { 9. Autoridad de acreditación Caribeña para La Educación em } \\
\text { Medicina y otras profesiones de la Salud }\end{array}$ & CAAM-HP & Caribe \\
\hline 10. Accreditation Council of Trinidad and Tobago & ACTT & \multirow{2}{*}{$\begin{array}{l}\text { Trinidade e } \\
\text { Tobago }\end{array}$} \\
\hline $\begin{array}{l}\text { 11. National Institute for Higher Education, research Science and } \\
\text { Technology }\end{array}$ & NIHERST & \\
\hline \multicolumn{3}{|l|}{ Hemisfério Norte } \\
\hline 12. Centre For Higher Education Research and Development & UMANITOBA & \multirow{6}{*}{ Canadá } \\
\hline 13. Postsecondary Education Quality Assessment Board & PEQAB & \\
\hline 14. Ontario College Quality Assurance Service & $\begin{array}{l}\text { COLLEGE } \\
\text { CVC }\end{array}$ & \\
\hline 15. Higher Education Quality Council Of Ontario & HEQCO & \\
\hline 16. Commission d'Évaluation de I'Enseignement Collégial & CEEC & \\
\hline 17. Campus Alberta Quality Council & CAQC & \\
\hline $\begin{array}{l}\text { 18. Sistema de Evaluación, Acreditacíon y Certificación de La } \\
\text { Educación Superior em América Latina y El Caribe }\end{array}$ & SEACESALC & \multirow[t]{2}{*}{ México } \\
\hline 19. Red Internacional de Evaluadores & RIEV & \\
\hline 20. Higher Education Research Institute (HERI) & GSEIS & \multirow[t]{9}{*}{ Estados Unidos } \\
\hline 21. Association for Instititucional Research & AIRWEB & \\
\hline 22. Institute for Higher Education Policy 48592 & IHEP & \\
\hline 23. The Boston College for International Higher Education & $\mathrm{BC}$ & \\
\hline $\begin{array}{l}\text { 24. Commission on Institutions of Higher Education/New England } \\
\text { Association of Schools and Colleges }\end{array}$ & NEASC & \\
\hline $\begin{array}{l}\text { 25. Council for accreditation of Counseling \& Related Educational } \\
\text { Programs }\end{array}$ & CACREP & \\
\hline 26. Council for Higher Education Accreditation & CHEA & \\
\hline 27. The Center for Quality assurance in International Education & CQAIE & \\
\hline $\begin{array}{l}\text { 28. Accrediting Commission for Community \& Junior Colleges } \\
\text { (Wasc) }\end{array}$ & ACCJC & \\
\hline
\end{tabular}

Fonte: RIACES. Rede Ibero-americana para a Acreditação da Qualidade da Educação Superior.

Disponível em: <http://www.riaces.org>. Acesso: 03 dez. 2013. 
Quadro 2 - Redes Internacionais de Agências de Acreditação no continente asiático

\begin{tabular}{|c|c|c|}
\hline \multicolumn{3}{|l|}{ CONTINENTE: Asiático } \\
\hline REDE & SIGLA & $\begin{array}{l}\text { PAÍS/ } \\
\text { SEDE }\end{array}$ \\
\hline 1. Red para La Calidad Asia-Pacífico & APQN & \multirow[t]{5}{*}{ China } \\
\hline 2. Hong Kong Council for Academic Accreditation & HKCCA & \\
\hline 3. Joint Quality Review Committee Limited & JQRC & \\
\hline $\begin{array}{l}\text { 4. The Guadong Center of Evaluation and Development Research for } \\
\text { Education }\end{array}$ & GDCEDRE & \\
\hline 5. Higher Education Evaluation Center of The Ministry of Education & PGZX & \\
\hline 6. Asia Pacific Research Institute & APRIM & $\begin{array}{c}\text { Ásia } \\
\text { Pacífico }\end{array}$ \\
\hline 7. Accreditation and Quality Assurance Commission & AQAC & Palestina \\
\hline 8. Higher Education Commission & HEC & Paquistão \\
\hline 9. Quality Assurance and Accreditation Council & QAACOUNCIL & Sri Lanka \\
\hline 10. Maldives Accreditation Board 2 & EMPLOYMENT & Maldivas \\
\hline 11. Lembaga Akkreditasi Negara (LAN)/National Accreditation Board & LAN & Malásia \\
\hline $\begin{array}{l}\text { 12. Accrediting Agency of Chartered Colleges and universities of the } \\
\text { Philippines (AACCUP) }\end{array}$ & AACCUPQA & \multirow[t]{2}{*}{ Filipinas } \\
\hline $\begin{array}{l}\text { 13. Philippine Accrediting Association of Schools, Colleges and } \\
\text { Universities }\end{array}$ & PAASCU & \\
\hline 14. The Mongolian National Council for education Accreditation & ACCMON & Mongólia \\
\hline 15. Private Universities Council, Ministry of Higher Education & PUC & Kuwait \\
\hline $\begin{array}{l}\text { 16. National Accreditation Center of Ministry Education \& Science of } \\
\text { Kazakhstan Republic }\end{array}$ & NAC & Cazaquistão \\
\hline 17. Accreditation Council of the Higher Education Institutions & MOHE & Jordânia \\
\hline 18. The Israeli Council for Higher Education & CHE & Israel \\
\hline $\begin{array}{l}\text { 19. Badan Akreditasi Nasional Perguruan Tinggi (BAN-PT), (National } \\
\text { Accreditation Board for Higher Education }\end{array}$ & BAN-PT & Indonésia \\
\hline 20. National assessment and Accreditation Council & NAACINDIA & \multirow[t]{2}{*}{ Índia } \\
\hline 21. Doeacc Society & DOEACC & \\
\hline 22. Commission for Academic Accreditation & CAA & $\begin{array}{l}\text { Emirados } \\
\text { Árabes }\end{array}$ \\
\hline 23. National Commission for Academic accreditation \& Assessment & NCAAA & $\begin{array}{l}\text { Arábia } \\
\text { Saudita }\end{array}$ \\
\hline
\end{tabular}

Fonte: RIACES. Rede Ibero-americana para a Acreditação da Qualidade da Educação Superior.

Disponível em: <http://www.riaces.org>. Acesso: 03 dez. 2013. 


\begin{tabular}{|c|c|c|}
\hline \multicolumn{3}{|l|}{ CONTINENTE: Europeu } \\
\hline REDE & SIGLA & PAÍS/SEDE \\
\hline $\begin{array}{l}\text { 1. Asociación Europea para El aseguramento de La calidad } \\
\text { em Educación Superior }\end{array}$ & ENQA & \multirow[t]{5}{*}{ Bélgica } \\
\hline 2. Asociación de Acreditación Evangélica Europea & EEAA & \\
\hline 3. Flemish Inter-University Council & VLIR & \\
\hline 4. Council of Flemish University Colleges & VLHORA & \\
\hline 5. European University Association & EUA & \\
\hline $\begin{array}{ll}\text { 6. } & \text { Red de agencias aseguradoras de La calidad em Educación } \\
\text { Superior de Europa Del este y Central }\end{array}$ & $\begin{array}{c}\text { CEE } \\
\text { NETWORK }\end{array}$ & \multirow[t]{3}{*}{ Alemanha } \\
\hline 7. Accreditation, Certfication, and Quality Assurance Institute & ACQUIN & \\
\hline $\begin{array}{ll}8 . & \text { Akkreditierungsagentur fur Studiengange der } \\
\text { Ingenieurwissenschaften, der Informatik, der } \\
\text { Naturwissenschaften und der Mathematik }\end{array}$ & ASIIN & \\
\hline 9. Red euroasiática para El aseguramiento de La calidad & EAQAN & \multirow[t]{4}{*}{ Rússia } \\
\hline $\begin{array}{l}\text { 10. Agency for Higher Education Quality Assurance and } \\
\text { Career Development (AQA) }\end{array}$ & AKKORK & \\
\hline 11. National accreditation Agency (NAA) & NICA & \\
\hline $\begin{array}{l}\text { 12. Research Centre for the problems of Quality in Specialist } \\
\text { Training (RC) }\end{array}$ & $\mathrm{RC}$ & \\
\hline 13. Agency for accreditation of higher education & AAAL & Albânia \\
\hline $\begin{array}{l}\text { 14. Rede Internacional de Agências de garantia da qualidade } \\
\text { no ensino superior }\end{array}$ & INQAAHE & \multirow[t]{2}{*}{ Holanda } \\
\hline $\begin{array}{l}\text { 15. Accreditation Organisation of the Netherlands and } \\
\text { Flanders }\end{array}$ & NVAO & \\
\hline 16. Agency for Science and Higher Education (ASHE) & AZVO & Croácia \\
\hline 17. Accreditation Commission of the Slovak Republic & AKREDKOM & Eslováquia \\
\hline 18. Finnish higher Education Evaluation Council & FINHEEC & Finlândia \\
\hline $\begin{array}{l}\text { 19. Comité National d`Évaluation des établissments publics à } \\
\text { caractère scientifique, culturel et professionnel }\end{array}$ & $\mathrm{CNE}$ & França \\
\hline 20. National Accreditation Board & NAB & Ghana \\
\hline $\begin{array}{l}\text { 21. British accreditation Council for Independent Further and } \\
\text { Higher Education }\end{array}$ & THE-BAC & \multirow[t]{3}{*}{ Grã-Bretanha } \\
\hline $\begin{array}{l}\text { 22. Centre for Higher Education Research and Information } \\
\text { (CHERI) }\end{array}$ & OPEN & \\
\hline 23. The Quality Assurance Agency for Higher Education & QAA & \\
\hline 24. Hungarían Accreditation Committee & MAB & \multirow[t]{2}{*}{ Hungria } \\
\hline 25. Institute for Higher Education Research & HIER.IIF & \\
\hline 26. Higher education and Training Awards Council & HETAC & \multirow[t]{2}{*}{ Irlanda } \\
\hline $\begin{array}{l}\text { 27. National Qualifications Authority of Ireland (Údarás } \\
\text { Náisiúnta Cáilíochtaí na hÉireann }\end{array}$ & NQAI & \\
\hline $\begin{array}{l}\text { 28. Instituto Nazionale per la valutazione del sistema educativo } \\
\text { di istruzione e di formazione }\end{array}$ & INVALSI & Itália \\
\hline 29. Agência de Avaliação e acreditação do Ensino Superior & A3ES & Portugal \\
\hline 30. Accreditation Commission of the Czech republic 29075 & MSMT & \multirow[t]{2}{*}{ República Tcheca } \\
\hline 31. Centre for Higher Education Studies (CHES) 3 & CSVS & \\
\hline $\begin{array}{l}\text { 32. The Romanian Agency for Quality Assurance in Higher } \\
\text { Education }\end{array}$ & ARACIS & Romênia \\
\hline 33. The Swedish National Agency for Higher Education & HSV & Suécia \\
\hline $\begin{array}{l}\text { 34. Panstwowa Komisja Akredytacyjna - The Polish State } \\
\text { Accreditation Committee }\end{array}$ & PKA & Polônia \\
\hline 35. Norwegian Agency for Quality Assurance in Education & NOKUT & Noruega \\
\hline $\begin{array}{l}\text { 36. Österreichische Qualitätssicherungsagentur (Austrian } \\
\text { Agency for Quality Assurance) }\end{array}$ & AUQA & Áustria \\
\hline $\begin{array}{l}\text { 37. Commission for Accreditation \& Quality Assessment } \\
\text { (CAQA) Komísija za Akreditaciju I proveru kvaliteta }\end{array}$ & MPS & Sérvia \\
\hline 38. Center for Quality Assessment in Higher Education & CQAHE & Lituânia \\
\hline
\end{tabular}




\begin{tabular}{|l|c|c|}
\hline 39. Estonian Higher Education Quality Accreditation Center & ARQUIMEDES & Estônia \\
\hline 40. Council of Educational Evaluation - Accreditation & MOEC & Chipre \\
\hline 41. Netherlands Quality Agency & NQA & \multirow{2}{*}{ Suíça } \\
\hline 42. Quality Assurance Netherlands Universities & QANU & \\
\hline
\end{tabular}

Fonte: RIACES. Rede Ibero-americana para a Acreditação da Qualidade da Educação Superior. Disponível em: <http://www.riaces.org>. Acesso: 03 dez. 2013.

\section{Quadro 4 - Redes Internacionais de Agências de Acreditação no continente africano}

\begin{tabular}{|c|c|c|}
\hline \multicolumn{3}{|l|}{ CONTINENTE: Africano } \\
\hline REDE & SIGLA & PAÍS/SEDE \\
\hline 1. National Universities Commission & NUC & Nigéria \\
\hline 2. Higher Education Quality Committee (HEQC) & $\mathrm{CHE}$ & Sudáfrica \\
\hline 3. African higher Education Research Online & UWC & \\
\hline 4. National Quality Assurance and Accreditation Committee & QAAP & Egito \\
\hline 5. Tertiary Education Commission & TEC & Maurícia \\
\hline 6. Higher Education Relevance and Quality Agency & HERQA & Etiópia \\
\hline
\end{tabular}

Fonte: RIACES. Rede Ibero-americana para a Acreditação da Qualidade da Educação Superior.

Disponível em: <http://www.riaces.org>. Acesso: 03 dez. 2013.

\section{Quadro 5 - Redes Internacionais de Agências de Acreditação na Oceania}

\begin{tabular}{|c|c|c|}
\hline \multicolumn{3}{|l|}{ CONTINENTE: Oceania } \\
\hline REDE & SIGLA & PAÍS/SEDE \\
\hline 1. Australian Universities Quality Agency & AUQA & \multirow{2}{*}{ Austrália } \\
\hline $\begin{array}{l}\text { 2. Higher Education Research and Development Society of } \\
\text { Australasia }\end{array}$ & HERDSA & \\
\hline ITP Quality & ITPQ & \multirow[t]{4}{*}{ Nova Zelândia } \\
\hline 4. New Zealand Qualifications Authority & NZQA & \\
\hline 5. New Zealand Universities Academic Audit Unit & AAU & \\
\hline 6. New Zealand Vice-Chancellors' Committee & NZVCC & \\
\hline
\end{tabular}

Fonte: RIACES. Rede Ibero-americana para a Acreditação da Qualidade da Educação Superior.

Disponível em: <http://www.riaces.org>. Acesso: 03 dez. 2013.

Pela retrospectiva realizada, verificou-se que há uma tendência mundial de criação e expansão de redes de associação de países com projetos conjuntos para regulamentar um padrão de qualidade nas universidades e em outras formas de ensino superior.

Para além das especificidades, é perceptível que essas redes comportam muitas semelhanças, em torno de um padrão para a qualidade, o que faz levantar uma série de pontos reflexivos que o estudo, globalmente, remeteu.

A pesquisa realizada no site da RIACES (2013) mostrou que havia 105 Agências Internacionais de Acreditação no mundo, assim distribuídas: 42 agências no continente europeu, 28 na América e 23 na Ásia, enquanto na África e Oceania havia somente seis. Tal 
ocorrência expressa a importância da educação superior como papel estratégico e reflete, diretamente, no desenvolvimento e na acumulação capitalista de cada nação.

No continente americano, apesar de existirem 28 agências - assim distribuídas: Hemisfério Sul, quatro agências; Hemisfério Central, sete agências; e Hemisfério Norte 17 agências -, há uma desproporcionalidade entre os respectivos hemisférios, pois os países do norte se destacam especialmente; os Estados Unidos, que, seguindo sua tradição de padrão de qualidade por meio da autorregulação independente do Estado, concentra nove agências, seguido do Canadá, com sete agências certificadoras.

Quanto à supremacia dos Estados Unidos, Eaton (2009, p. 21) informa que o Governo americano, há muito, estuda ações para assumir o controle direto sobre os padrões de qualidade e as ofertas de cursos de ensino superior, muito semelhante ao que a União Europeia já fez, ou seja, também definir os padrões de garantia de qualidade para o Espaço Norte-Americano de Educação Superior.

Tal como detalham Leite e Genro (2012, p. 8), Hartmann reconhece que, frente ao capitalismo global, há um "poder imperial normativo central por parte dos EUA e um novo poder imperial, tipo imperialismo benevolente da União Europeia”, que lança regras e normas aceitas por outras regiões sobre a educação superior.

No continente asiático, há 23 agências, e o maior destaque é para a China, que mantém cinco agências, seguida das Filipinas e da Índia, cada uma com duas agências. Os demais países têm apenas uma agência.

No continente europeu, concentram-se 42 agências; assim distribuídas: cinco na Bélgica, quatro na Alemanha, quatro na Rússia, e duas na Irlanda, Suíça e Grã-Bretanha e Hungria; os demais países mantêm apenas uma agência. Do ponto de vista europeu, isso encontra conformidade com o que fora previamente definido pelo Processo de Bolonha ${ }^{6}$ (1999), explícito no documento denominado Standards and Guidelines for Quality Assurance in the European Higher Education Area, organizado pela European Association for Quality Assurance in Higher Education (ENQA), cujo conteúdo trata das normas e das diretrizes para a garantia de qualidade no Espaço Europeu de Educação Superior ${ }^{7}$ (EEES, 2010); ou seja,

\footnotetext{
${ }^{6}$ Baseia-se numa estruturação (reforma) do ensino superior em três ciclos: o primeiro ciclo (licenciatura) com duração de três anos; o segundo ciclo (mestrado) com duração de dois anos; e o terceiro ciclo (doutoramento) com duração de três anos. Algumas áreas terão uma estrutura de estudos diferente, mas esta é a duração mais frequente dos três ciclos. Atualmente, são 46 os países europeus signatários da Declaração de Bolonha.

${ }^{7}$ Teve sua gênese numa declaração assinada em Sorbonne (1988), pelos ministros de Educação da Alemanha, Itália, França e Reino Unido. Nessa reunião, era pretendido iniciar uma mudança no ensino superior europeu, cujo objetivo seria o reconhecimento mútuo de graus acadêmicos por parte das instituições europeias, de forma a facilitar a mobilidade dos estudantes em toda a Europa. Um EEES atrativo passaria a garantir a qualidade do 
onde se encontra o cadastro das Agências de Avaliação e Acreditação reconhecidas e certificadas na União Europeia (UE).

Esse dispositivo legal é responsável pelo alinhamento obrigatório da maioria dos sistemas universitários da Europa em favor da constituição de sistemas de Acreditação de caráter heterônomo, em detrimento à tradição de sistemas de avaliação autônomos, cuja inversão tem sido capaz de articular esquemas de certificação que, simultaneamente, atendem a quesitos nacionais de fortalecimento da qualidade dentro da "Europa do conhecimento", como o aumento da competitividade e a perspectiva de internacionalização, oriundas da integração do bloco econômico.

Contudo, observa-se que as maiores concentrações de agências neste continente estão na Bélgica, Rússia e Alemanha, muitas das quais já existiam antes da Declaração de Bolonha. Nos demais países, há menor proporção quanto à presença de órgãos reguladores da qualidade, porém o número de países que aderiram à criação de agências é maior, obviamente, para atender aos ditames de Bolonha.

Analisando-se os casos do continente europeu e do continente americano, supõe-se que a maior concentração de agências se justifica no fato da expansão e da massificação da educação superior, acompanhada pela heterogeneidade dos estudantes e docentes, pela diversificação e diferenciação de novos tipos e modalidades de ensino superior, o que gerou desconfiança nos sistemas, nas instituições, nos diplomas e nos profissionais, levando à necessidade de novos mecanismos de aferição da qualidade, agora por meio da autorregulação, ou seja, no modelo de supervisão de Estado. De fato, conforme o estudo, ambos os continentes despontam na frente dos demais com a maior concentração de agências.

No continente africano, encontra-se um total de seis agências, assim distribuídas: duas na Sudáfrica e uma na Nigéria, Egito, Maurícia e Etiópia. Na Oceania, encontram-se seis agências, quatro concentradas na Nova Zelândia e duas na Austrália.

Sobre a importância de maior ou menor concentração e distribuição das agências nos diferentes países, ficou claro que, em escala mundial, independente do seu desenvolvimento, depois da Declaração de Bolonha, a maioria dos países, tanto os que tinham tradição como os de pouca familiaridade com processos de Acreditação, todos procuraram aperfeiçoar e/ou

ensino superior e da investigação, da diversidade das instituições e de projetos de cooperação transnacional. Ganhou destaque a qualidade na Cimeira de Berlim (2003), quando foi declarada a intenção de apresentar em 2010 os sistemas educativos europeus como uma referência de qualidade em nível mundial mediante o refrão: "Europa do conhecimento", tendo a ENQA elaborado um conjunto de normas e diretrizes para a garantia da qualidade, para serem utilizadas pelas Agências de Avaliação e Acreditação. 
organizar estruturas públicas ou privadas de agências para certificar, legalmente, suas atividades na esfera do ensino superior.

\begin{abstract}
De um país a outro, são muitas as semelhanças em relação à metodologia e às finalidades atribuídas aos processos de acreditação. Mas também há muitas diferenças, que se deve a graus de desenvolvimento dos sistemas de educação superior, a questões culturais e a dificuldades técnicas. Enquanto nos Estados Unidos a acreditação já tem uma longa e sólida experiência, nos países latino-americanos se verificam uma grande heterogeneidade e notáveis assimetrias, que vão desde as diferenças quanto aos marcos normativas, projetos nacionais, índices de desigualdade sociais etc. Tudo isso está associado aos perfis dos sistemas, especialmente a sua capacidade de promover cobertura com equidade e qualidade científica, e ao grau de desenvolvimento das instituições de educação superior (DIAS SOBRINHO, 2006, p. 15).
\end{abstract}

Confirmada a tendência de que a reforma implantada pelo Processo de Bolonha no ensino superior está provocando reflexos além do continente europeu, em função do aumento da competitividade em nome de uma política internacional indutora de garantia da qualidade, pode-se prever, em médio prazo, um aumento de agências em todos os continentes, além de uma revisão nos moldes da acreditação, até então implementada nos Estados Unidos.

\title{
5 Algumas considerações
}

As ideias expostas no corpo deste texto encaminham para as seguintes considerações.

O processo de regulamentação e garantia de qualidade na educação superior, se consubstancia numa categoria de análise histórica, pois foi a antiguidade europeia que deu uma vaga noção de controle e padrão de qualidade, através de regulamentos outorgados pela Igreja e pelo Rei. Assim, as universidades e a educação superior se desenvolveram num contexto de competição por controle, cujos interesses corporativos, por muitos séculos, foram o grande empecilho para a melhoria da qualidade dos padrões da educação superior.

O surgimento da universidade moderna no século XIX foi um marco importante, pois deu caráter universal e garantiu livre acesso a todos os interessados na carreira docente. $\mathrm{O}$ mérito disso está na contraposição ao uso da regulamentação local que vigorava antes.

Foi na América do Norte que surgiu, no século XX, a experiência mais consolidada sobre a garantia da qualidade na educação superior, ou seja, o pioneirismo dos Estados Unidos, que rompeu com a dependência da Igreja e do Estado em matéria do controle de qualidade, alinhando-se à experiência da área empresarial.

A partir das mudanças globais e das novas exigências para a educação superior, observa-se que as práticas de acreditação se espalharam em alguns países, com base na experiência norte-americana, fato que evoluiu e culminou, velozmente, para a criação de aglomerados denominados de Redes de Agências Internacionais de Acreditação, distribuídas 
nos cinco continentes, as quais passaram a ser redimensionadas à luz da competitividade induzida pela reforma do ensino superior com base nas diretrizes e normas para a qualidade delimitadas na Declaração de Bolonha.

Com base na RIACES (2013), são mais de cem Redes de Agências Internacionais de Acreditação operando no mundo, das quais se espera que, minimamente, consigam separar o joio do trigo, pois o diferencial das Redes está na instauração de um movimento de cooperação transcontinental mais aberto, global, flexível, menos nacional e mais internacional entre os órgãos, países, regiões, pesquisadores e estudantes, objetivando, de fato, a garantia da qualidade do ensino superior.

Depois da Declaração de Bolonha, percebeu-se que a maioria dos países, tanto os que tinham tradição como os de pouca familiaridade com processos de Acreditação, todos procuraram aperfeiçoar e/ou organizar estruturas públicas ou privadas de agências para certificar, legalmente, suas atividades na esfera do ensino superior.

Confirmada tal tendência em maior ou menor grau, em função do aumento da competitividade em nome de uma política internacional de asseguramento da garantia da qualidade, pode-se prever que haverá, nos próximos anos, um aumento de agências de certificação da qualidade nos continentes africano, asiático, europeu e na Oceania, como também em países dos hemisférios Sul e Central do continente americano, além de uma revisão nos moldes da Acreditação, até então implementada nos Estados Unidos.

Para concluir, afirma-se que a atual política de garantia da qualidade para o ensino superior representa o aperfeiçoamento dos esforços empregados nos diferentes temposespaços, pois o que antes se traduziu na competição entre o clero, o rei e a elite hoje se consubstancia num fenômeno de proporções globais a ser enfrentado: a competividade dos mercados.

\section{Referências}

AMARAL, Alberto. Tendências recentes dos sistemas de avaliação do ensino superior na Europa. Sísifo, Lisboa, n. 12, maio/ago. 2010.

BROCK, Colin. Raízes históricas e sociais de regulamentação e acreditação da educação superior e garantia de qualidade. In: EDUCAÇÃO superior em tempo de transformação: novas dinâmicas para a responsabilidade social. Relatório GUNI. Tradução de Vera Muller. Porto Alegre: EDIPUCRS, 2009.

DECLARAÇÃO DE BOLONHA. 1999. Disponível em: <http://www.mctes.pt/docs/ficheiros/Declaracao_deBolonha.pdf>. Acesso em: 28 abr. 2014. 
DIAS SOBRINHO, José. Acreditação da Educação Superior. 2006. Disponível em: <http://www.portal.mec.gov.br/índex.php?option=com_docman\&task>. Acesso em: 17 julho. 2015.

EATON, J. Espaço Internacional de Acreditação. In: EDUCAÇÃO superior em tempo de transformação: novas dinâmicas para a responsabilidade social. Relatório GUNI. Tradução de Vera Muller. Porto Alegre: EDIPUCRS, 2009.

ESPAÇO EUROPEU DE ENSINO SUPERIOR (EEES). Conferência Ministerial de Budapeste-Viena. Budapeste, 2010.

GUNI - Global University Network for Innovation. Educação Superior em um tempo de transformação: novas dinâmicas para a responsabilidade social. Tradução de Vera Muller. Porto Alegre: EDIPUCRS, 2009.

LEITE, Denise; GENRO, M. Elly H. Quo vadis? Avaliação e internacionalização da Educação Superior na América Latina. In: POLÍTICAS de Evaluación Universitaria en América Latina: perspectivas críticas. Buenos Aires: CLACSO; Instituto de Investigaciones Gino Germani, 2012. p. 763-785.

NEAVE, G.; VUGHT, F. Conclusion. In: NEAVE, G.; VUGHT, Van (Ed.). Government and higher relationships across three continents: the winds of chang. London: Pergamon Press, 1994. p. 187-206.

REISBERG, Liz. Onde se encontra a discussão sobre qualidade: estratégias e ambiguidades. Revista CEAV online, Campinas, p. 1-35, 2011. Disponível em: <http://www.gr.unicamp.br/ceav/revista/content/pdf/quality_assurance_lizreisberg_pt.pdf>. Acesso em: 10 mar. 2015.

RIACES - Rede Ibero-americana para a Acreditação da Qualidade da Educação Superior. Disponível em: 〈http://www.riaces.org>. Acesso: 03 dez. 2013.

SCHEELE, Ko. Lincence to kill: about accreditation issues and James Bond. 2004. Disponível em: <http://www.enqa.eu/files/workshop_material/Netherlands.pdf >. Acesso em: 6 abr. 2015.

SOUSA SANTOS, Boaventura de. A universidade no século XXI: para uma reforma democrática e emancipatória da universidade. São Paulo: Cortez, 2010.

${ }^{1}$ Glades Tereza Felix Universidade Federal de Santa Maria | Centro de Educação| Departamento de Administração Escolar Santa Maria | RS | Brasil. Contato: gladesfelix@ hotmail.com ORCIID (iD http://orcid.org/0000-0002-1668-7586 